\title{
Palmar fasciitis and arthritis in a patient with an extraovarian adenocarcinoma of the coelomic epithelium
}

\author{
P H B Willemse, N H Mulder, H J van de Tempel, J G Aalders, D Th Sleijfer
}

\begin{abstract}
A 54 year old woman presented with an intraabdominal adenocarcinoma of primary coelomic origin and a syndrome of palmar fasciitis and arthritis, which was exacerbated during treatment by combination chemotherapy with intravenous carboplatin 300 $\mathrm{mg} / \mathrm{m}^{2}$ and cyclophosphamide $750 \mathrm{mg} / \mathrm{m}^{2}$, while the tumour responded well.
\end{abstract}

Some definite types of connective tissue diseases have been associated with malignant disease and even heralded its presence. The best known examples are dermatomyositis, ${ }^{1}$ hypertrophic osteoarthropathy, ${ }^{2}$ and neuromyopathy. ${ }^{3}$ The syndrome of palmar fasciitis, a disease with rapidly progressive flexion contractures of both hands and arthritis of the wrists and larger joints, occurs rarely and is less known. Women are more commonly affected and, additionally, have ovarian cancer. We report a patient with an extraovarian adenocarcinoma of the coelomic epithelium who displayed this syndrome.

\section{Case report}

A 54 year old white woman presented in September 1986 with increasing abdominal distension and stool frequency. Weight loss amounted to $8 \mathrm{~kg}$ over three months. The menses had ceased at 51 years, and she was gravida 2 para 2 . On physical examination she had an asthenic habitus and cachectic, height $162 \mathrm{~cm}$, weight $56 \mathrm{~kg}$, with diffusely pigmented skin, more apparent on pressure points-for example, over the knuckles, elbows, and knees. The right knee and proximal interphalangeal joint of the third right finger were swollen and painful. There was no history of previous arthritis or Raynaud's disease. A physical examination showed massive ascites, and after abdominal paracentesis a mobile mass of about $12 \mathrm{~cm}$ was felt in the left upper abdomen. Gynaecological examination showed a normal uterus, the adnexa could not be properly felt. Laboratory investigations showed raised lactic dehydrogenase $(785$ (normal $<245$ $\mathrm{U} / \mathrm{l})$ ) and raised tumour marker CA 125 (1478 (normal <36 U/1)), but a normal carcinoembryonic antigen and haemoglobin concentration. Antinuclear factor, antiperinuclear factor, and IgM rheumatoid factor were negative; the $C$ reactive protein and erythrocyte sedimentation rate were all normal. There was no eosinophilia. An abdominal ultrasound showed a large amount of ascites and a massively infiltrated omentum, but a normal liver, no signs of ureteral obstruction, and normal ovaries and uterus. Gastroscopy and a barium enema were also normal. An exploratory laparotomy was then performed. The omentum was massively infiltrated with tumour, and throughout the whole abdominal cavity nodules up to $2 \mathrm{~mm}$ were present. No tumour was felt in pancreas, gall bladder, stomach, large and small bowel. The uterus appeared normal, but on the surface of the otherwise apparently normal ovaries there were also numerous superficial tumour nodules. Microscopical examination of the intraperitoneal implants showed an undifferentiated serous cystadenocarcinoma, but in both ovaries only superficial tumour implants were found. Additional immunofluorescence testing of this tissue was negative for carcinoembryonic antigen and positive for epithelial membrane antigen, concordant with an adenocarcinoma, probably of primary coelomic origin.

About three weeks after the operation she received six monthly courses of combination chemotherapy with intravenous carboplatin 300 $\mathrm{mg} / \mathrm{m}^{2}$ and cyclophosphamide $750 \mathrm{mg} / \mathrm{m}^{2}$. The ascites disappeared and ultrasound scan and tumour marker CA 125 indicated a partial remission. During cytostatic treatment she complained of increasing pain in all finger joints and in the right knee, which became swollen and warm. Despite treatment with oral naproxen $250 \mathrm{mg}$ four times a day she developed progressive swelling of the metacarpophalangeal and interphalangeal joints of both hands, and of the elbows and complained of stiff shoulders. A bone scan showed increased activity in the small and large joints (fig 1). A flexion contracture of the intrinsic hand muscles and palmar fascia

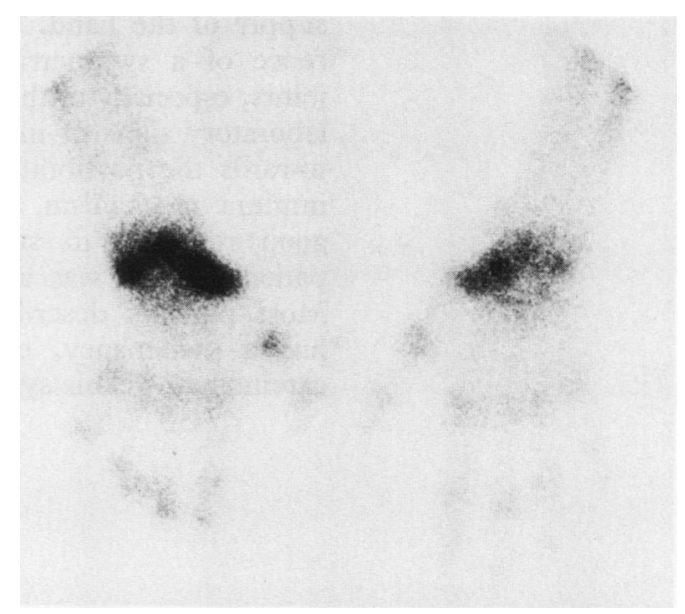

Figure 1 Technetium-99m diphosphonate bone scan, detailed view of both hands, showing accumulation of tracer in the small joints of the wrist. 


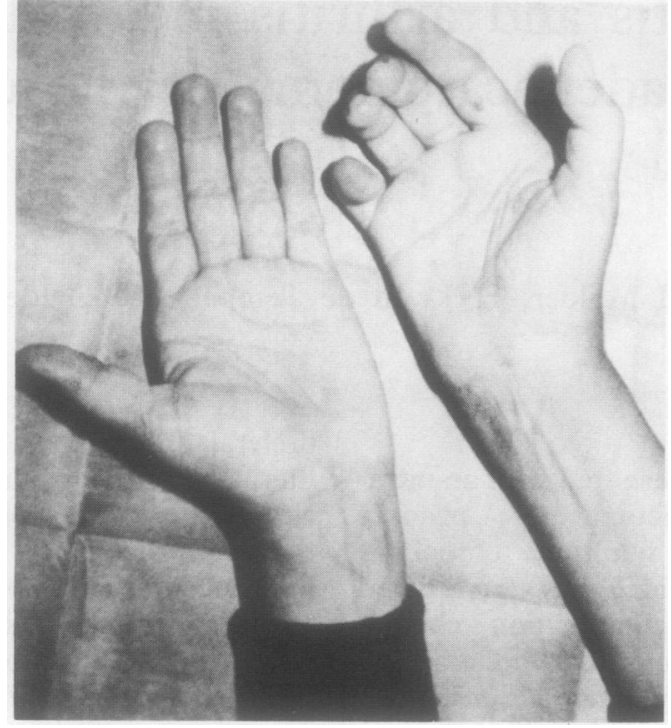

Figure 2 Right hand of the patient shows flexion contracture, most pronounced in fourth and fifth finger, swelling of metacarpophalangeal joints, and muscular atrophy.

developed, resembling a Dupuytren contracture, being most marked in the right hand (fig 2). Radiographs of both hands showed paraarticular osteopenia of the right hand compared with the left. Symptoms and inflammatory signs decreased after institution of prednisolone $3 \times 15$ mg orally. There was a decrease in pain and tenderness, while the contracture of the right palmar fascia was somewhat ameliorated and the pain and swelling of the right knee subsided. The symptoms did not flare up when the tumour became progressive again, but remained silent until her death supervened 17 months after the start of treatment.

\section{Discussion}

The signs and symptoms of this patient agree with the description of palmar fasciitis and arthritis described by Medsger in six patients with ovarian cancer. ${ }^{4}$ The clinical picture of the palmar fasciitis is the same as that of reflex sympathetic dystrophy, which occurs after traumatic degeneration of the sympathetic nerve supply of the hand. The simultaneous occurrence of a symmetrical arthritis of multiple joints, especially of the arms, together with the laboratory signs of inflammation, points more towards the possibility of a generalised (auto) immune mechanism. This is supported by the good response to steroid treatment in our patient, which was also reported by others. Most patients described with this syndrome had a malignancy, especially ovarian adenocarcinoma. ${ }^{49}$ This syndrome can also occur in non-malignant diseases, such as chronic alcoholism leading to cirrhosis, ${ }^{10}$ and after the use of drugs such as phenobarbitone or isoniazid. ${ }^{10-13}$

In malignancy the cause of the syndrome remains an enigma. Interestingly, however, mesothelial tissue seems to play a part, as it must in all patients with ovarian cancer. This suggests a common mechanism, by which the patient may be sensitised to mesothelial cells or underlying connective tissue, leading to inflammation of other endothelial sites-that is, the joints. One report in search of underlying immune phenomena mentions IgG deposits in the inflamed and fibrosing palmar tissue. ${ }^{4}$ Other authors, however, could not induce stimulation of cultured fibroblasts with the patients' malignant ascites, thus failing to prove the presence of an antigenic stimulus derived from a tumour. ${ }^{6}$

It is our opinion, that in this syndrome, when a response to standard non-steroidal, antiinflammatory drugs fails, steroid treatment should not be withheld, in view of its prompt effects, the irreversible contracture of the hands, and the limited prospects of survival of these patients. Prompt treatment will be possible when the progressive nature of the syndrome is recognised earlier despite the rarity of this syndrome. Conversely, the existence of a malignant disorder should be suspected when a patient presents with this disorder, which may precede the symptoms of the malignancy by several months.

1 Barnes B E. Dermatomyositis and malignancy. A review of the literature. Ann Intem Med 1976; 84: 68-76.

2 Mackenzie A H, Scherbel A L. Connective tissue syndrome associated with carcinoma. Geriatrics 1963; 18: 745-53.

3 Croft P B, Wilkinson $M$. The incidence of carcinomatous neuromyopathy in patients with various types of carcinoma. Brain 1965; 88: 427-34.

4 Medsger T A Jr, Dixon J A, Farwood V F. Palmar fasciitis and polyarthritis associated with ovarian carcinoma. Ann Interm Med 1982; 96: 424-31.

5 Baron M. Palmar fasciitis, polyarthritis and carcinoma. Ann Intern Med 1982; $97: 616$.

6 Shiel W C, Prete P E, Jason M, Andrews B S. Palmar fasciitis and arthritis with ovarian and non-ovarian carcinomas. $\mathrm{Am}$ f Med 1985; 79: 640-4.

7 Goldberg E, Kennedy S F. Reflex sympathetic dystrophy: recognition and management in gynecologic oncology. Gymecol Oncol 1979; 8: 288-95.

8 Michaels R M, Sorber J A. Reflex sympathetic dystropy as a probable paraneoplastic syndrome: case report and literature review. Arthritis Rheum 1984; 27: 1183-5.

9 Pfinsgraff J, Buckingham R B, Keister S R, et al. Palmar fasciitis and arthritis associated with malignant neoplasms [Abstract]. Proceedings of the tenth southeastem regional meeting, American Rhermatism Association. 1983.

10 Seaman J M, Goble M, Madsen L, Steigerwald J C. Fasciitis and polyarthritis during antituberculous therapy. Arthritis Rhew 1985; 28: 1179-84.

11 Van der Korst J K, Colenbrander H, Cats A. Phenobarbital and the shoulder-hand syndrome. Ann Rhewm Dis 1966; 25: 553-5.

12 Pojer J, Radivojevic M, Williams T F. Dupuytren's disease: its association with abnormal liver function in alcoholism and epilepsy. Arch Intern Med 1972; 129: 561-6.

13 Zarafonetis D J D, Kalas J P. Serotonin degradation by ceruloplasmin and its inhibition by isoniazid and iproniazid. Am 7 Med Sci 1960; 239: 203-6. 